\title{
Functional neurological disorder and multiple sclerosis: a systematic review of misdiagnosis and clinical overlap
}

\author{
Dennis WalzI ${ }^{1}$ D . Andrew J. Solomon ${ }^{2}$ (D) Jon Stone ${ }^{1}$ (D)
}

Received: 27 September 2020 / Revised: 24 January 2021 / Accepted: 28 January 2021 / Published online: 21 February 2021

(c) The Author(s) 2021

\begin{abstract}
Multiple sclerosis (MS) and functional neurological disorder (FND) are both diagnostically challenging conditions which can present with similar symptoms. We systematically reviewed the literature to identify patients with MS who were misdiagnosed with FND, patients with FND who were misdiagnosed with MS, and reports of patients with both conditions. In addition to FND, we included studies of patients with other functional and psychiatric disorders where these caused symptoms leading to investigation for or a diagnosis of MS, which in a different context would likely have been labeled as FND. Our review suggests that MS is one of the most common causes of misdiagnosis of FND and vice versa. We discuss the clinical errors that appear to result in misdiagnoses, such as over-reliance on psychiatric comorbidity when making a diagnosis of FND or over-reliance on neuroimaging for the diagnosis of MS, and practical ways to avoid them. Comorbidity between these two conditions is also likely common, has been poorly studied, and adds complexity to diagnosis and treatment in patients with both MS and FND. Misdiagnosis and comorbidity in a landscape of emerging evidence-based treatments for both MS and FND are issues not only of clinical importance to the care of these patients, but also to treatment trials, especially of MS, where FND could be a hidden confounder.
\end{abstract}

Keywords Multiple sclerosis $\cdot$ Functional neurological disorder $\cdot$ Conversion disorder $\cdot$ Psychogenic $\cdot$ Misdiagnosis

\section{Introduction}

Multiple sclerosis (MS) and functional neurological disorder (FND) are both diagnostically challenging conditions presenting at times with similarly disabling paroxysmal, fluctuating, and multifocal neurological symptoms. They also share a similar epidemiology, with a preponderance of female to male patients, and both are common conditions in neurological practice [1].

Misdiagnosis of MS or FND causes harm to patients, most generally in the form of a delay to diagnosis and initiation of proper treatment. Misdiagnosis of FND in patients who have MS may result in irreversible disability as a consequence of delays in the initiation of disease modifying therapy (DMT). However, DMTs carry unnecessary side-effects

Jon Stone

Jon.Stone@ed.ac.uk

1 Centre for Clinical Brain Sciences, University of Edinburgh, Chancellor's Building, Edinburgh, UK

2 Larner College of Medicine at the University of Vermont, Burlington, VT, USA and risks for patients with FND who are misdiagnosed with MS. Patients with FND who are misdiagnosed with MS have a prognosis similar to MS [2] but which may improve with more modern evidence-based treatment [3]. Misdiagnosis can also cause psychological harm in patients if they partially shape their identity around a diagnosis of MS or FND that they are later informed is incorrect $[4,5]$.

FND may also present as a comorbid condition in patients with an accurate diagnosis of MS, in which case both conditions warrant treatment. Failure to detect comorbidity between FND and MS may result in unnecessary treatment of misdiagnosed relapses, and unwarranted escalation to higher risk DMTs in patients with MS, and could also present an important confounder for MS research efforts that include assessment of clinical disability status.

In several previous studies, we noticed that when people who have MS are initially misdiagnosed, FND is often one of the conditions for which it is mistaken [6]; and when people with FND are misdiagnosed, often the erroneous diagnosis is MS [7]. Our findings prompted us to search the literature for further data concerning the diagnostic overlap between MS and FND. 
Our aim in this review is to summarize what is known about how often FND is misdiagnosed in patients with MS, how often MS is misdiagnosed in patients with FND, as well as comorbidity between these two disorders. We discuss potential sources of error in the diagnosis of each condition, and implications for both clinical care and future research.

\section{Methods}

We searched English-language studies on MEDLINE from 1965 to April 2020 using the search:

("diagnostic error*" OR "misdiagnosis") AND ("multiple sclerosis" OR ("functional neurological disorder*" OR "functional disorder*" OR "conversion disorder*" OR "somatization" OR "psychogenic" OR "dissociative" OR "hysteria"))

The abstracts of 512 papers yielded by this search were screened for relevance. We excluded case reports. We hand searched references of articles identified for additional studies relevant to this review. We included any study that focused on a diagnostic change between MS and FND, or their comorbidity. In addition to FND, we also included and reported studies reporting patients misdiagnosed as having another functional disorder (including fibromyalgia), a psychiatric disorder, or "non-specific symptoms". Patients are usually suspected of having MS because they have motor or sensory symptoms. We looked at a broader range of conditions on the grounds that in many cases, it seems likely that clinicians may have made no diagnosis (e.g., non-specific symptoms) or focused on a comorbid disorder that they considered to be relevant or was perhaps dominant, such as anxiety or fibromyalgia, even though those diagnoses do not encompass the type of motor and sensory symptoms that typically lead to the evaluation for, or the diagnosis of, MS. For example, if a patient received a diagnosis of MS, but later was found not to have MS but in fact depression, it seems likely that in a different context, a diagnosis of FND would have been made, as depression could not have otherwise caused neurological symptoms suggestive of MS.

\section{Patients with multiple sclerosis who are misdiagnosed with functional neurological disorder}

FND, also referred to as psychogenic, dissociative, and conversion disorder, consists of motor, sensory or seizure symptoms that can be identified as relating to a functional disorder. The core diagnostic feature in motor and sensory presentations is the finding of impairment in voluntary motor or sensory function which can be shown under other circumstances to be intact. A positive Hoover's sign of leg weakness or positive tremor entrainment test are examples
[1]. A number of studies, particularly if the numerous terms used to describe FND are considered, have found that MS may be misdiagnosed as FND (Table 1).

Patients with MS often experience a period of diagnostic delay prior to receiving a diagnosis of MS [8]. The reasons for this are multifactorial, and often involve systemic barriers to healthcare access. Although many studies have reported such diagnostic delay in MS care [8-12], only a few have documented specific misdiagnoses that were responsible for such delays (Table 1).

In a 1988 study, researchers identified all patients with a diagnosis of MS in prevalence assessments in 1976 and 1981 in a region of New Zealand, and found that out of ten who had initially been seen by psychiatrists with symptoms attributable to MS, eight were diagnosed with a variety of psychiatric diagnoses for symptoms such as weakness, balance incoordination, sensory symptoms, and vision loss [13]. Four (50\%) were given a diagnosis of "hysterical conversion" or similar. It is possible that these particular misdiagnoses might have been prevented using current MS diagnostic criteria that incorporate imaging techniques. However, similar findings were noted from an MS tertiary care center in Israel in 2003. 29 out of 50 (58\%) consecutive MS patients self-reported having initially been given 41 different diagnoses prior to a diagnosis of MS; of those 29, $9(31 \%)$ were diagnosed with a psychiatric disorder including anxiety, somatization, or conversion disorder (FND) [14]. In this study, eight additional patients reported that a physician had diagnosed them with "no problem" despite presenting with motor or sensory symptoms, and perhaps they would have been more explicitly diagnosed with FND by a different provider. In a 2019 study, 30 (23\%) of 128 patients with MS at five tertiary care centers in Portugal had received psychiatric diagnoses prior to a diagnosis of MS [15]. Similarly, in a 2020 study at a tertiary care center in Ukraine, 53 patients were initially misdiagnosed before receiving the correct diagnosis of $\mathrm{MS}$, including one $(2 \%)$ with generalized anxiety disorder and six (11\%) with "other neuropsychiatric disorders" [16].

Further information about the misdiagnosis of MS as FND comes from cohort studies of FND (Table 1). A systematic review of diagnostic change in FND, incorporating 27 studies and 1466 patients with a mean duration of 5 years going back to the 1950s, found that misdiagnoses of FND had been stable at approximately $4 \%$ since 1970 . Revised diagnoses were reported in 68 out of 123 misdiagnosed patients; the most common were epilepsy (19\%), multiple sclerosis (9\%), and movement disorders (9\%) [7]. In a subsequent prospective cohort study of patients referred to neurology outpatient clinics in Scotland, only 4 (0.4\%) out of 1030 patients with FND acquired a subsequent unexpected new diagnosis which better explained the original symptoms, one of whom had MS [17]. In a 14-year prospective case-control 
Table 1 Studies reporting patients with multiple sclerosis who were initially misdiagnosed with functional neurological disorder (FND), functional disorder or psychiatric disorder

\begin{tabular}{|c|c|c|c|c|c|c|}
\hline \multicolumn{7}{|c|}{ Cohort studies of multiple sclerosis } \\
\hline \multirow[t]{2}{*}{ Study } & \multirow{2}{*}{\multicolumn{2}{|c|}{ Year data collected }} & \multirow[t]{2}{*}{ Methodology } & \multirow{2}{*}{$\begin{array}{l}\text { Misdiagnosed } \\
\text { total }\end{array}$} & \multicolumn{2}{|c|}{ MS misdiagnoses which were: } \\
\hline & & & & & $\begin{array}{l}\text { FND, func- } \\
\text { tional disorder } \\
\text { or psychiatric } \\
\text { disorder }\end{array}$ & FND alone \\
\hline Skegg et al. [13] & \multicolumn{2}{|l|}{1976 and 1981} & $\begin{array}{l}\text { Review of the psychiatry records of } 91 \text { patients with } \\
\text { MS in New Zealand }\end{array}$ & $8 / 91(9 \%)^{\mathrm{a}}$ & $8 / 8(100 \%)$ & $4 / 8(50 \%)$ \\
\hline Levin et al. [14] & \multicolumn{2}{|l|}{2003} & $\begin{array}{l}\text { Survey of } 50 \text { patients with MS in Israel regarding } \\
\text { misdiagnosis before confirmation of MS }\end{array}$ & $29 / 50(58 \%)$ & $9 / 29(31 \%)$ & Not stated \\
\hline Aires et al. [15] & \multicolumn{2}{|l|}{ 2010-2015 } & $\begin{array}{l}\text { Review of causes of diagnostic delay in } 285 \text { patients } \\
\text { with MS in Portugal }\end{array}$ & $\begin{array}{r}128 / 285 \\
(45 \%)\end{array}$ & $30 / 128(23 \%)$ & Not stated \\
\hline Ivaniuk et al. [16] & \multicolumn{2}{|l|}{$2007-2018$} & $\begin{array}{l}\text { Review of records of } 128 \text { patients with MS in } \\
\text { Ukraine for initial misdiagnosis }\end{array}$ & $53 / 128(41 \%)$ & $7 / 53(13 \%)$ & Not stated \\
\hline \multicolumn{7}{|c|}{ Cohort studies of functional neurological disorder } \\
\hline Study & $\begin{array}{l}\text { Year of } \\
\text { original } \\
\text { diagnosis }\end{array}$ & \multicolumn{3}{|c|}{ Methodology } & $\begin{array}{l}\text { Misdiagnosed } \\
\text { total }\end{array}$ & $\begin{array}{l}\text { Patients with MS } \\
\text { among patients } \\
\text { misdiagnosed as } \\
\text { FND }\end{array}$ \\
\hline Stone et al. [7] & 1949-2001 & \multicolumn{3}{|c|}{$\begin{array}{l}\text { Systematic review of studies on diagnostic outcome of adults with a } \\
\text { diagnosis of FND (or older synonyms) }\end{array}$} & $\begin{array}{c}123 / 1466 \\
(8 \% ; 4 \% \\
\text { since } 1970)\end{array}$ & $6 / 68(9 \%)$ \\
\hline Stone et al. [17] & $2002-2004$ & \multicolumn{3}{|c|}{$\begin{array}{l}\text { Prospective cohort study of patients with medically unexplained symp- } \\
\text { toms as rated by neurologist with 19-month follow-up }\end{array}$} & $4 / 1030(0.4 \%) \quad 1$ & $1 / 4(25 \%)$ \\
\hline Gelauff et al. [18] & $2000-2003$ & \multicolumn{3}{|c|}{$\begin{array}{l}\text { Prospective cohort study of patients with functional limb weakness with } \\
\text { 14-year follow-up }\end{array}$} & $1 / 89(1 \%)$ & $1 / 1(100 \%)$ \\
\hline
\end{tabular}

${ }^{\text {a }}$ This study only looked at diagnostic error in patients who had attended psychiatry clinics

study of 89 patients with functional limb weakness published in 2019, the only person who had a diagnosis at follow-up which in hindsight may have been a better explanation for their symptoms had been diagnosed with MS. This patient had comorbid FND and MS [18]. While these studies demonstrate low absolute numbers of patients with MS who were initially misdiagnosed as having FND, large cohort studies of FND focused on diagnosis are uncommon. Unlike MS cohort studies, these studies employed a restricted and more accurate definition of FND, whereas in the MS literature, functional disorders and psychiatric disorders are often grouped together with inconsistent terminology.

It is difficult to provide a reliable estimation of the frequency of misdiagnosis of MS as FND owing to heterogeneity in design, outcome measures, diagnostic criteria, and terminology used. As a rough guide, from the FND cohort studies presented here, we would summarize that the overall misdiagnosis rate of FND is probably between 1 and $4 \%$ and that around $10 \%$ of these misdiagnoses may be MS related; in other words, around $0.1-0.4 \%$ of people with FND.

\section{Patients with functional neurological disorder who are misdiagnosed with multiple sclerosis}

\section{Patients with functional and psychiatric disorders suspected of having MS}

Studies reporting a diagnostic change in patients "suspected" of having MS are not clearly a misdiagnosis per se, since in many cases while MS is being entertained as a diagnosis, evaluation remains ongoing. However, if a sufficient number of patients referred for evaluation of suspected MS are found to have FND, it is reasonable to assume that some proportion of such patients are at risk for misdiagnosis of MS. Multiple studies spanning three decades reporting referral patterns to academic MS centers in several countries have consistently 
demonstrated that patients with FND are indeed frequently referred for evaluation for a diagnosis of MS (Table 2).

In a study of 400 consecutive patients referred to a tertiary MS research unit between 1979 and 1983 (and thus predating the common use of MRI in MS diagnosis) in Canada, 14 out of 52 (27\%) patients who did not have MS had psychiatric conditions, including two with "hysteria" [19]. In a retrospective review of 281 new patient evaluations at a tertiary MS center in the United States between 2001 and 2003, 63 out of 186 (34\%) patients who did not have MS or possible MS had "possible psychiatric disease" [20]. These patients with psychiatric diagnoses had one or more of "somatoform disorders" (76\%), mood disorders (33\%), and/or anxiety disorders (11\%) [21]. Conversely, there were no diagnoses of FND or psychiatric disorders in a Dutch retrospective review from 1998 to 2001, where 116 out of 377 (31\%) consecutive patients referred for a second opinion to a tertiary MS center had diagnoses other than MS or demyelinating disease [22]. Of these patients, 29 (25\%) had another neurological disease, none of whom had FND or psychiatric disorders (although five "single diagnoses" were not specified). This study is particularly limited because in a significant proportion of patients, including $80 \%$ at followup 7 years later, no diagnosis could be identified [23].

In an American tertiary MS center from 2004 to 2007, the most common diagnosis was "psychiatric disease" in 53 out of 70 (76\%) patients who had been referred for MS evaluation but did not have MS [24]. A retrospective review of all patients presenting to a Brazilian demyelinating disease center from 1994 to 2013 found that 495 out of 1599 (31\%) did not have MS, of whom 108 (22\%) had "other diagnosis", which included psychiatric disorders, although the proportion was not specified [25]. In Lebanon and Kuwait between 2011 and 2015, the most common alternative diagnosis in 131 patients referred with clinical or radiological suspicion of MS to two tertiary MS centers for diagnostic confirmation of MS, who did not have a confirmed diagnosis of MS, was "psychogenic" in 19 (16\%) [26].

A study across 22 MS centers in Italy published in 2019 included 667 patients who were referred for suspected MS and followed up for up to three years if their diagnosis remained uncertain. Of 163 patients who did not have MS or clinically isolated syndrome, nine $(6 \%)$ had psychiatric or functional diagnoses: five had "psychiatric disorder" and four had fibromyalgia [27]. Notably, this study also highlighted a large number of patients with "nonspecific neurologic symptoms" associated "with atypical MRI" $(n=10)$ and "with atypical MRI lesions of suspected vascular origin" $(n=40)$. These are likely to represent a heterogenous group so we have not included them in Table 2, although at least some may have attracted a diagnosis of a functional disorder in other settings. Lastly, in a recent prospective pilot study evaluating an emerging MRI diagnostic biomarker for MS ("central vein sign") in patients with diagnostic uncertainty, three out of 23 (13\%) patients who did not have MS had FND or functional sensory symptoms [28].

Table 2 Studies reporting final diagnoses in patients referred for evaluation to tertiary MS centers

\begin{tabular}{|c|c|c|c|c|}
\hline Study & Year data collected & $\begin{array}{l}\text { Centre where evaluation } \\
\text { of MS took place }\end{array}$ & $\begin{array}{l}\text { Patients with diagnoses } \\
\text { other than MS }\end{array}$ & $\begin{array}{l}\text { Proportion of diagnoses other than } \\
\text { MS which were FND, functional } \\
\text { disorder or psychiatric diagnoses }\end{array}$ \\
\hline Murray and Murray [19] & $1979-1983$ & Tertiary center, Canada & $52 / 400(13 \%)$ & $\begin{array}{l}\text { "Psychiatric conditions": } 14 / 52(27 \%) \\
\text { [anxiety }(n=6), \text { depression }(n=4), \\
\text { hysteria }(n=2)]\end{array}$ \\
\hline Nielsen et al. [22, 23] & 1998-2001 & $\begin{array}{l}\text { Tertiary center, Neth- } \\
\text { erlands }\end{array}$ & $116 / 377(31 \%)$ & $\begin{array}{l}\text { No diagnoses of FND or psychiatric } \\
\text { disorders } \\
\text { "No certain diagnosis could be } \\
\text { made": } 87 / 116\end{array}$ \\
\hline $\begin{array}{l}\text { Carmosino et al. [20], } \\
\text { Brousseau et al. [21] }\end{array}$ & 2001-2003 & $\begin{array}{l}\text { Tertiary center, United } \\
\text { States }\end{array}$ & $186 / 281(66 \%)$ & $\begin{array}{l}\text { "Possible psychiatric": } 63 / 186(34 \%) \\
\text { [somatoform }(n=48), \text { mood disor- } \\
\text { ders }(n=21), \text { anxiety }(n=7)]\end{array}$ \\
\hline Rolak and Fleming [24] & 2004-2007 & $\begin{array}{l}\text { Tertiary center, United } \\
\text { States }\end{array}$ & $70 / 142(49 \%)$ & "Psychiatric": 53/70 (76\%) \\
\hline Bichuetti et al. [25] & 1994-2013 & Tertiary center, Brazil & $495 / 1599(31 \%)$ & $\begin{array}{l}\text { Not specified } \\
\text { "Other diagnosis" 108/495 }\end{array}$ \\
\hline Yamout et al. [26] & 2011-2016 & $\begin{array}{l}\text { Tertiary centers, Leba- } \\
\text { non and Kuwait }\end{array}$ & $131 / 431(30 \%)$ & "Psychogenic": 19/131 (15\%) \\
\hline Calabrese et al. [27] & 2014 & 22 tertiary centers, Italy & $163 / 667(24 \%)$ & $\begin{array}{l}\text { Total: } 9 / 163(6 \%) \text { ["psychiatric" } \\
(n=5), \text { "fibromyalgia" }(n=4)]\end{array}$ \\
\hline Clarke et al. [28] & 2015-2018 & $\begin{array}{l}\text { Tertiary center, United } \\
\text { Kingdom }\end{array}$ & $23 / 35(66 \%)$ & $\begin{array}{l}\text { FND or functional sensory symptoms: } \\
3 / 23(13 \%)\end{array}$ \\
\hline
\end{tabular}


In summary, at tertiary MS centers across a wide geographic distribution and over a long duration of time encompassing numerous revisions to MS diagnostic criteria, patients who ultimately had psychiatric disorder, or functional disorder including FND, have been consistently referred for evaluation for a diagnosis of MS. The frequency of such referrals of patients with FND for MS diagnostic evaluations raises the chance of MS misdiagnoses in these patients.

\section{Patients with functional neurological disorder misdiagnosed as having multiple sclerosis}

In a 2012 survey of $122 \mathrm{MS}$ specialists, $95 \%$ reported that they had evaluated in the last year at least one patient who they strongly felt did not have MS despite having carried a diagnosis of MS for at least a year [29]. Many had seen numerous such patients over the preceding year. When asked to recall alternate diagnoses in such misdiagnosed patients, the fourth most common disorder reported was psychiatric disorder (45\%) and the sixth was fibromyalgia (31\%).

Several studies of varying size and methodological approaches have described characteristics of patients misdiagnosed with MS, including numerous patients with final correct diagnoses of functional and psychiatric disorders (Table 3).

In a 1981 study including 69 patients misdiagnosed with MS, 35 (51\%) had a functional or psychiatric diagnosis: 16 had a functional disorder, 14 had anxiety/hyperventilation, three had "hysterical conversion", and two had depression [30]. A 1986 case series describing ten patients who were misdiagnosed with MS found one patient whose final diagnosis was "hysteria" [31]. A 1997 study of 366 patients with a diagnosis of MS referred for a second opinion to Charles Poser found 130 misdiagnosed patients, including $28(22 \%)$ with chronic fatigue syndrome and eight (6\%) with "psychiatric disorder" or "post-traumatic syndrome" [32]. Of note, these studies predate the incorporation of MRI into MS diagnostic criteria in 2001 and may be less representative of contemporary misdiagnosis.

Table 3 Studies reporting patients with functional or psychiatric disorder misdiagnosed as MS

\begin{tabular}{|c|c|c|c|c|}
\hline Study & Year data collected & Methodology & Total misdiagnosed & $\begin{array}{l}\text { Proportion misdiagnosed with FND, } \\
\text { functional disorder or psychiatric } \\
\text { disorder }\end{array}$ \\
\hline $\begin{array}{l}\text { Hankey and Stewart- } \\
\text { Wynne [30] }\end{array}$ & 1981 & $\begin{array}{l}\text { Reviewed records of } \\
\text { patients either diagnosed } \\
\text { with or told they might } \\
\text { have MS }\end{array}$ & $69 / 387(17 \%)$ & $\begin{array}{l}\text { All categories: } 35 / 69(51 \%) \\
\text { Functional disorder }(n=16) \text {, anxiety/ } \\
\text { hyperventilation }(n=14) \text {, hysteri- } \\
\text { cal conversion }(n=3) \text {, depression } \\
(n=2)\end{array}$ \\
\hline Rudick et al. [31] & 1986 & $\begin{array}{l}\text { Case series of ten patients } \\
\text { who were misdiagnosed } \\
\text { with MS }\end{array}$ & $10(\mathrm{n} / \mathrm{a})$ & "Hysteria": 1/10 (10\%) \\
\hline Poser [32] & 1997 & $\begin{array}{l}\text { Review of patients with } \\
\text { MS diagnosis referred } \\
\text { for second opinion }\end{array}$ & $130 / 366(36 \%)$ & $\begin{array}{l}\text { All categories: } 36 / 130(28 \%) \\
\text { Chronic fatigue syndrome }(n=28), \\
\text { post-traumatic syndrome }(n=5), \\
\text { psychiatric disorders }(n=3)\end{array}$ \\
\hline Walzl et al. [34] & 2002-2004 & $\begin{array}{l}\text { Prospective cohort study } \\
\text { of new neurology out- } \\
\text { patients including } 209 \\
\text { with MS }\end{array}$ & $9 / 209(4 \%)$ & $\begin{array}{l}\text { All categories: } 3 / 9(33 \%) \\
\text { Anxiety }(n=2) \text {, chronic fatigue syn- } \\
\text { drome }(n=1)\end{array}$ \\
\hline Solomon et al. [6] & 2014-2015 & $\begin{array}{l}\text { Multicenter case series } \\
\text { comprised of patients } \\
\text { misdiagnosed with MS }\end{array}$ & $110(\mathrm{n} / \mathrm{a})$ & $\begin{array}{l}\text { All categories: } 28 / 110(25 \%) \\
\text { Fibromyalgia }(n=16) \text {, conversion or } \\
\text { psychogenic disorder }(n=12)\end{array}$ \\
\hline De Seabra et al. [36] & 2009-2016 & $\begin{array}{l}\text { Retrospective study } \\
\text { reviewing patient } \\
\text { records at an MS clinic } \\
\text { between } 2009 \text { and } \\
2016 \text { by applying } 2010 \\
\text { McDonald criteria }\end{array}$ & $44 / 635(7 \%)$ & $\begin{array}{l}\text { All Categories: } 2 / 44(5 \%) \\
\text { Dissociative disorder }(n=1), \text { fibromy- } \\
\text { algia }(n=1)\end{array}$ \\
\hline Kaisey et al. [35] & 2016-2017 & $\begin{array}{l}\text { Patients with a prior } \\
\text { established diagnosis } \\
\text { of MS were reviewed } \\
\text { in clinic and evaluated } \\
\text { for fulfilment of } 2010 \\
\text { McDonald criteria }\end{array}$ & $43 / 241(18 \%)$ & Fibromyalgia: 2/43 (5\%) \\
\hline
\end{tabular}


In the Scottish Neurological Symptoms Study (SNSS), 9 out of $209(4 \%)$ patients with a diagnosis of MS or demyelination [33] at baseline had an alternative diagnosis at 18 months follow-up, of whom three (33\%) had a functional disorder or psychiatric diagnosis at follow-up (anxiety and chronic fatigue syndrome) [34]. In a 2016 multicenter case series reporting 110 patients misdiagnosed with MS, 12 (11\%) had "conversion or psychogenic disorder", the fourth most common diagnosis. Also of note, $16(15 \%)$ were diagnosed with fibromyalgia, and $13(12 \%)$ with non-specific or non-localizing neurologic symptoms with abnormal MRI [6]. In contrast, in a 2019 study in California, there were no cases of FND among 43 misdiagnosed MS patients referred to two MS tertiary care centers, although there were two cases (5\%) of fibromyalgia [35]. An additional recent study in 2020 in Portugal reported 44 misdiagnoses in 635 patients (7\%) referred to an MS clinic between 2009 and 2016 [36]. Of those, one had dissociative disorder and another fibromyalgia, and nine had non-specific MRI changes with unclear explanations for their symptoms.

Once again, it is hard to distill the data to a 'headline figure', but it can be seen that the frequency of MS misdiagnosis for all conditions ranged from 4 to $36 \%$. The differential diagnosis of MS is broad, but within this misdiagnosed group, functional or psychiatric disorders were consistently seen, making up between 5 and $51 \%$ of patients with these diagnostic errors. The estimates therefore seem somewhat higher in this direction than for patients erroneously misdiagnosed as FND.

\section{Sources of clinical error in misdiagnosis}

The literature reviewed above supports that the misdiagnosis of FND as MS, and vice versa, is not infrequent. Both FND and MS can result in disabling paroxysmal or fluctuating neurological symptoms in young adults, and accurate diagnosis in both disorders relies on a skilled clinical assessment. There remains no highly specific biomarker for either MS or FND. However, consensus clinical criteria for MS have performed with high accuracy when used correctly [37]. Diagnostic criteria for FND based on DSM-5 emphasize finding evidence of clinical incompatibility with recognized diseases, which in practice requires the presence of positive signs of internal inconsistency and incongruity [1]. Clinical practice suggests that FND diagnoses do generally remain stable $[7,17,18]$, but more work needs to be done to define the disorder and its many symptoms and subtypes.

Clinician reliance on a history of psychiatric comorbidity or of adverse experience is one of the most common reasons for an incorrect diagnosis of FND [38]. Such factors may be important in formulation or treatment when present, but are so common that they are not of diagnostic value. Additionally, failing to adequately rely on clear positive clinical examination signs of FND to make the diagnosis [1], or placing weight on a "bizarre" presentation which the clinician finds hard to explain [38] are common errors from our experience. Conversely, patients who are older, male and do not conform to stereotypes about FND may experience overdiagnosis with disease diagnoses such as MS.

Data from studies focused on MS [6,35] suggest that misapplication and misinterpretation of MS diagnostic criteria may be responsible for many cases of misdiagnosis. The McDonald criteria require successive clinical assessments. In cases of FND misdiagnosed as MS, it is likely that the McDonald criteria are applied in patients presenting without one of the required "typical syndromes" for MS, "objective evidence" on neurological examination or paraclinical testing of a corroborating central nervous system lesion. Instead, an over-reliance on brain MRI imaging abnormalities that can be attributed to a variety of other common causes (including small vessel ischemic disease, migraine, or healthy aging) that fulfill the MRI portion of the McDonald criteria, accompanied by non-specific or non-CNS localizing neurological symptoms, may often fit the profile of patients with FND misdiagnosed with MS. Conversely, the widespread adoption of MRI for the diagnosis of MS that has occurred since the completion of a number of the above studies may have resulted in fewer patients with MS having been misdiagnosed with FND.

Neither MS nor FND should be approached as a diagnosis of exclusion. The clinical assessments required to fulfill the McDonald criteria, and specific examination findings in FND (i.e., positive signs) increase specificity for a diagnosis of each disorder. Diagnosing MS in patients with MRI abnormalities and with no better explanation for their neurological symptoms increases the risk of misdiagnosis. Similarly, making a diagnosis of FND in a patient with a normal MRI and unexplained non-specific neurological symptoms is incorrect and likely to lead to misdiagnosis.

\section{Comorbidity of functional neurological disorder and multiple sclerosis}

Is a diagnosis of FND in a patient with MS always an error? Most neurologists specializing in MS recognize that they commonly see patients who clearly have an accurate diagnosis of MS, yet also have symptoms and/or signs which suggest that they have a comorbid functional disorder. This kind of FND comorbidity is well recognized for other neurological conditions. For example, up to $20 \%$ of patients with dissociative non-epileptic seizures have a history of, or comorbid, epilepsy [39], and studies of Parkinson's disease are increasingly highlighting FND as a comorbidity, especially in the prodromal period [40].

Neurologists as far back as Charcot recognized that patients with MS and functional disorders could be intertwined. Gowers wrote that "hysterical and emotional disturbance are 
common (in MS), even in men" [41]; Oppenheim wrote that "Multiple sclerosis is frequently associated with hysteria" [42]; and Russell Brain wrote in 1930 that "Hysterical symptoms, such as pareses and ataxia, seem to occur more often in association with disseminated sclerosis than with any other organic disease of the nervous system" [43]. Wilson, on the other hand, viewed "hysteria" and multiple sclerosis as separate, and although he recognized that "hysteria" was common, when diagnosed in the early stages, or "pre-disseminated" form of MS, he thought it represented a misdiagnosis [44].

Although widely acknowledged, there is scant data on the prevalence of FND comorbidity with MS [45, 46]. In a study of 366 patients with MS in Denmark in the 1970s and 80 s, five (1\%) had psychiatric admissions for "hysteric" neuroses in relation to and after the onset of MS [47]. A case series of four similar patients with both MS and "hysteria" was published in JAMA in 1980 [48]. In a 2011 study of new neurology outpatients with a diagnosis of neurological disease, 32 out of 252 (13\%) patients with MS were rated by the neurologist as having symptoms only "somewhat" or "not at all" explained by that disease [33]. One unpublished conference abstract from 2019 reported that $7.5 \%$ of 120 German MS patients had "inconsistent findings that could not be explained neurologically" [49].

Studies of MS "pseudorelapses" in children [50] and adults [51,52] have highlighted that FND can be a potential cause of an apparent MS relapse. Although relapse was not specified as a reason for the visits, "non-organic" presentations accounted for 12 out of 371 (3\%) rapid access visits to an MS service in Wales, UK [52].

The comorbidity of MS with psychiatric diagnoses has been more extensively studied. A comprehensive systematic review of 118 studies on psychiatric comorbidities in MS found that psychiatric comorbidities were common; in particular, the prevalence of diagnosed anxiety and depression were estimated at 21.9 and $23.7 \%$, respectively [53]. A study of comorbidity in patients with MS found that the 668 patients who also self-reported mental comorbidities experienced a delay to diagnosis of MS, and were more likely to have severe, rather than mild, disability two years after diagnosis [54]. A nationwide cohort study in Denmark did not find a statistically significant increase in diagnostic delay in patients with psychiatric comorbidity, perhaps due to a small number of patients $(n=75)$, but there was a significantly increased mortality [55]. It is important to understand that FND and functional disorders are not synonyms for psychiatric disorder; they are conditions in their own right that do occur without psychiatric comorbidity. Nonetheless, FND and functional disorders also are known for a high frequency of psychiatric comorbidity as well as disturbances in emotional regulation that have also been found in MS [56]. Therefore, the presence of depression or anxiety could add to both the misdiagnosis of FND and MS.
In conclusion, the topic of FND and MS comorbidity is poorly researched, but the studies we have do suggest it occurs, and following a renaissance in FND diagnosis and evidence-based treatment, is now worthy of more careful study.

\section{Clinical care and research}

What are the consequences of misdiagnosing FND in a patient with MS? Difficulties will be especially magnified if the neurologist making the original FND diagnosis did so in a way that failed to validate the patient's symptoms or provide onward treatment. Whereas in the past, missing a diagnosis of MS could have been said not to have led to a change in prognosis, that is no longer the case with newer disease modifying agents [57].

The implications of misdiagnosis of MS in patients who have FNDs include unnecessary treatment of MS and its accompanying side-effects and risks, delay to diagnosis and treatment of FND, and psychological harm as a result of misdiagnosis. In one study, $31 \%$ of patients misdiagnosed with MS experienced unnecessary morbidity as a result of misdiagnosis, most commonly due to unnecessary immunomodulatory therapy and treatment side-effects [6]. Traditionally, neurologists may have considered that accidentally diagnosing MS in someone with FND was less harmful because of a lack of established treatment options for FND. However, the scientific landscape around FND has changed considerably in the last 10 years [1]. Patients with FND erroneously diagnosed with MS miss out on increasingly evidence-based treatment for their functional symptoms. For example, a randomized controlled trial of specialized physiotherapy for functional motor symptoms found that $72 \%$ of patient had improvements in mobility sustained at 6 month follow-up compared to $18 \%$ in a control arm having nonspecialized physiotherapy [3].

The diagnosis of a neurodegenerative disease such as MS can have a life-altering psychological effect on patients. Patients can shape their identity around their diagnosis, and it is difficult for neurologists to remove a diagnosis of MS without concern of causing yet more harm to the patient [4, 5]. This is perhaps especially the case when the new diagnosis is one of a functional disorder, when the neurologist may feel less equipped to help than they were with an MS diagnosis [58].

Identifying comorbid FND and MS can lead to fundamental differences in treatment. The treatment of FND depends firstly on establishing with the patient that they have a condition which is potentially reversible, and related to a problem in the "software" of the nervous system, rather than a "hardware" problem as seen in established MS. Second, the type of physical rehabilitation that has been developed for FND uses a transparent explanatory model for the 
disorder which takes advantage of the inconsistencies seen on examination and turns them into therapeutic opportunities during therapy [3]. So, a patient with FND may be discouraged from thinking too hard about their walking and to actively use distraction techniques to improve function, whereas in therapy for someone with MS, the patient may be asked to concentrate hard on the affected limb. Furthermore, recognition of FND comorbidity in patients with MS has important consequences for the assessment of MS relapses. In such patients, additional paraclinical testing, such as MRI, might be necessary to confirm "objective evidence" of a CNS lesion responsible for symptoms or challenging neurological exam findings.

Lastly, the identification of patients with MS and FND comorbidity may have a further benefit for MS research. Patients with FND comorbidity may increase "signal to noise ratio" in clinical trials of new therapies for MS with subjectively rated clinical outcome measures. If reliable ways could be found to exclude such patients, this could lead to better data from trials of MS therapeutic agents, a concept that has also been proposed in relation to functional cognitive disorders and dementia trials [59].

\section{Conclusions}

MS and FND are common conditions that are not infrequently mistaken for one another, and which may co-exist more often than is currently acknowledged. Improved clinical recognition and broader research efforts focused on the overlap of these two disabling disorders has potentially important consequences for the care of patients with MS and FND and for treatment studies in both conditions.

Acknowledgements The authors thank Stoyan Popkirov (Ruhr-Universität Bochum) for highlighting some additional studies as well as Kateryna Piliavska and Roger Schmidt. JS is supported by a National Health Service Research Scotland Career Fellowship.

Author contributions AJS and JS conceptualized the study. DW performed the literature search and wrote the first draft of the manuscript. All authors commented on previous versions of the manuscript and revised the manuscript for intellectual content. All authors read and approved the final manuscript.

Funding No funding reported.

Availability of data and materials Not applicable.

\section{Compliance with ethical standards}

Conflict of interest D. Walzl reports no disclosures. A. J. Solomon participated in consulting for Alexion, Biogen, EMD Serono, Celgene, received research funding from Biogen, participated in non-promotional speaking for EMD Serono, and is participating in contracted research with Actelion, Novartis, and Roche. J. Stone receives honoraria from UpToDate, carries out expert witness work in relation to FND, runs a free self-help website for patients with FND, is on the advisory board for FND Hope and FND Action and is secretary of the FND society.

Ethics approval The manuscript does not contain clinical studies or patient data.

Consent to participate This review article did not include primary research involving human participants.

Consent for publication All authors agreed with the content and gave explicit consent to submit.

Open Access This article is licensed under a Creative Commons Attribution 4.0 International License, which permits use, sharing, adaptation, distribution and reproduction in any medium or format, as long as you give appropriate credit to the original author(s) and the source, provide a link to the Creative Commons licence, and indicate if changes were made. The images or other third party material in this article are included in the article's Creative Commons licence, unless indicated otherwise in a credit line to the material. If material is not included in the article's Creative Commons licence and your intended use is not permitted by statutory regulation or exceeds the permitted use, you will need to obtain permission directly from the copyright holder. To view a copy of this licence, visit http://creativecommons.org/licenses/by/4.0/.

\section{References}

1. Espay AJ, Aybek S, Carson A et al (2018) Current concepts in diagnosis and treatment of functional neurological disorders. JAMA Neurol 75:1132-1141

2. Gelauff J, Stone J, Edwards M, Carson A (2014) The prognosis of functional (psychogenic) motor symptoms: a systematic review. J Neurol Neurosurg Psychiatry 85:220-226

3. Nielsen G, Buszewicz M, Stevenson F, Hunter R, Holt K, Dudziec M, Ricciardi L, Marsden J, Joyce E, Edwards MJ (2017) Randomised feasibility study of physiotherapy for patients with functional motor symptoms. J Neurol Neurosurg Psychiatry 88:484-490

4. Solomon AJ, Klein E (2013) Disclosing a misdiagnosis of multiple sclerosis: do no harm? Contin Lifelong Learn Neurol 19:1087-1091

5. Coebergh JA, Wren DR, Mumford CJ (2014) 'Undiagnosing' neurological disease: how to do it, and when not to. Pract Neurol 14:436-439

6. Solomon AJ, Bourdette DN, Cross AH et al (2016) The contemporary spectrum of multiple sclerosis misdiagnosis. Neurology 87:1393-1399

7. Stone J, Smyth R, Carson A, Lewis S, Prescott R, Warlow C, Sharpe M (2005) Systematic review of misdiagnosis of conversion symptoms and "hysteria." BMJ 331:989

8. Marrie RA, Cutter G, Tyry T, Hadjimichael O, Campagnolo $\mathrm{D}$, Vollmer T (2005) Changes in the ascertainment of multiple sclerosis. Neurology 65:1066-1070

9. Kelly SB, Chaila E, Kinsella K, Duggan M, McGuigan C, Tubridy N, Hutchinson M (2011) Multiple sclerosis, from referral to confirmed diagnosis: an audit of clinical practice. Mult Scler J 17:1017-1021

10. Willumsen JS, Aarseth JH, Myhr K-M, Midgard R (2020) High incidence and prevalence of MS in Møre and Romsdal County, 
Norway, 1950-2018. Neurol Neuroimmunol Neuroinflamm 7:e713

11. Kingwell E, Leung AL, Roger E, Duquette P, Rieckmann P, Tremlett H (2010) Factors associated with delay to medical recognition in two Canadian multiple sclerosis cohorts. J Neurol Sci 292:57-62

12. Fernández O, Fernández V, Arbizu T, Izquierdo G, Bosca I, Arroyo R, García Merino JA, De Ramón E (2010) Characteristics of multiple sclerosis at onset and delay of diagnosis and treatment in Spain (The Novo Study). J Neurol 257:1500-1507

13. Skegg K, Corwin PA, Skegg DCG (1988) How often is multiple sclerosis mistaken for a psychiatric disorder? Psychol Med 18:733-736

14. Levin N, Mor M, Ben-Hur T (2003) Patterns of misdiagnosis of multiple sclerosis. Isr Med Assoc J 5:489-490

15. Aires A, Barros A, Machado C et al (2019) Diagnostic delay of multiple sclerosis in a portuguese population. Acta Med Port 32:289-294

16. Ivaniuk A, Marusich T, Solodovnikova Y, Son A (2020) Is initial misdiagnosis associated with reaching disability milestones in patients with multiple sclerosis? Medicina 56:170

17. Stone J, Carson A, Duncan R et al (2009) Symptoms "unexplained by organic disease" in 1144 new neurology out-patients: how often does the diagnosis change at follow-up? Brain 132:2878-2888

18. Gelauff JM, Carson A, Ludwig L, Tijssen MAJ, Stone J (2019) The prognosis of functional limb weakness: a 14-year case-control study. Brain 142:2137-2148

19. Murray TJ, Murray SJ (1984) Characteristics of patients found not to have multiple sclerosis. Can Med Assoc J 131:336-337

20. Carmosino MJ, Brousseau KM, Arciniegas DB, Corboy JR (2005) Initial evaluations for multiple sclerosis in a university multiple sclerosis center. Arch Neurol 62:585-590

21. Brousseau K, Arciniegas D, Carmosino M, Corboy J (2007) The differential diagnosis of Axis I psychopathology presenting to a university-based multiple sclerosis clinic. Mult Scler J 13:749-753

22. Nielsen JM, Korteweg T, Barkhof F, Polman CH, Uitdehaag BMJ, Polman CH (2005) Overdiagnosis of multiple sclerosis and magnetic resonance imaging criteria. Ann Neurol 58:781-783

23. Nielsen JM, Uitdehaag BMJ, Polman CH (2008) Long-term followup of suspected though unconfirmed MS. Mult Scler J 14:985-987

24. Rolak LA, Fleming JO (2007) The differential diagnosis of multiple sclerosis. Neurologist 13:57-72

25. Bichuetti DB, Falcão AB, de Boulos F, C, de Morais MM, Lotti CB de C, Fragomeni M de O, Campos MF, de Souza NA, Oliveira EML, (2014) The profile of patients followed at the Neuroimmunology Clinic at UNIFESP: 20 years analysis. Arq Neuropsiquiatr 73:304-308

26. Yamout BI, Khoury SJ, Ayyoubi N, Doumiati H, Fakhreddine M, Ahmed SF, Tamim H, Al-Hashel JY, Behbehani R, Alroughani R (2017) Alternative diagnoses in patients referred to specialized centers for suspected MS. Mult Scler Relat Disord 18:85-89

27. Calabrese M, Gasperini C, Tortorella C et al (2019) "Better explanations" in multiple sclerosis diagnostic workup: a 3-year longitudinal study. Neurology 92:e2527-e2537

28. Clarke MA, Samaraweera APR, Falah Y, Pitiot A, Allen CM, Dineen RA, Tench CR, Morgan PS, Evangelou N (2020) Single Test to ARrive at Multiple Sclerosis (STAR-MS) diagnosis: a prospective pilot study assessing the accuracy of the central vein sign in predicting multiple sclerosis in cases of diagnostic uncertainty. Mult Scler J 26:433-441

29. Solomon AJ, Klein EP, Bourdette D (2012) "Undiagnosing" multiple sclerosis: the challenge of misdiagnosis in MS. Neurology 78:1986-1991

30. Hankey GJ, Stewart-Wynne EG (1987) Pseudo-multiple sclerosis: a clinico-epidemiological study. Clin Exp Neurol 24:11-19
31. Rudick RA, Schiffer RB, Schwetz KM, Herndon RM (1986) Multiple sclerosis: the problem of incorrect diagnosis. Arch Neurol 43:578-583

32. Poser CM (1997) Misdiagnosis of multiple sclerosis and $\beta$-interferon. Lancet 349:1916

33. Stone J, Carson A, Duncan R et al (2011) Which neurological diseases are most likely to be associated with "symptoms unexplained by organic disease." J Neurol 259:33-38

34. Walzl D, Carson AJ, Stone J (2019) The misdiagnosis of functional disorders as other neurological conditions. J Neurol 266:2018-2026

35. Kaisey M, Solomon AJ, Luu M, Giesser BS, Sicotte NL (2019) Incidence of multiple sclerosis misdiagnosis in referrals to two academic centers. Mult Scler Relat Disord 30:51-56

36. de Seabra MML, Abreu PMP, Mendonça MTS, Reis JJCS, Sá MJPM, Guimarães Ferreira Almeida JC (2020) Diagnostic revisions in multiple sclerosis. Clin Exp Neuroimmunol 11:171-175

37. Thompson AJ, Banwell BL, Barkhof F et al (2018) Diagnosis of multiple sclerosis: 2017 revisions of the McDonald criteria. Lancet Neurol 17:162-173

38. Stone J, Reuber M, Carson A (2013) Functional symptoms in neurology: mimics and chameleons. Pract Neurol 13:104-113

39. Kutlubaev MA, Xu Y, Hackett ML, Stone J (2018) Dual diagnosis of epilepsy and psychogenic nonepileptic seizures: systematic review and meta-analysis of frequency, correlates, and outcomes. Epilepsy Behav 89:70-78

40. Wissel BD, Dwivedi AK, Merola A et al (2018) Functional neurological disorders in Parkinson disease. J Neurol Neurosurg Psychiatry 89:566-571

41. Gowers WR (1893) A manual of diseases of the nervous system. J. and A. Churchill, London

42. Oppenheim H, Mayer EE (1900) Diseases of the nervous system: a textbook for students and practitioners of medicine (transl.). J. B. Lippincott Co., Philadelphia, London

43. Brain WR (1930) Critical review: disseminated sclerosis. QJM 91:343-391

44. Wilson SAK (1931) The approach to the study of hysteria. J Neurol Psychopathol 11:193-206

45. Aring CD (1965) Observations on multiple sclerosis and conversion hysteria. Brain 88:663-674

46. Herman MN, Sandok BA (1967) Conversion symptoms in a case of multiple sclerosis. Mil Med 132:816-818

47. Stenager E, Jensen K (1988) Multiple sclerosis: correlation of psychiatric admissions to onset of initial symptoms. Acta Neurol Scand 77:414-417

48. Caplan LR, Nadelson T (1980) Multiple sclerosis and hysteria: lessons learned from their association. JAMA 243:2418-2421

49. Piliavska K, Maier-Ring D, Dantlgraber M, Schmidt R, Dettmers C (2019) Prevalence of medically unexplained symptoms in multiple sclerosis and their association with psychological factors. In: Annual rehabilitation in multiple sclerosis (rims) conference

50. Carbonell CF, Benson L, Rintell D, Prince J, Chitnis T (2014) Functional relapses in pediatric multiple sclerosis. J Child Neurol 29:943-946

51. Merwick A, Sweeney BJ (2008) Functional symptoms in clinically definite MS - pseudo-relapse syndrome. Int MS J 15:47-51

52. Tallantyre EC, Causon EG, Harding KE, Pickersgill TP, Robertson NP (2015) The aetiology of acute neurological decline in multiple sclerosis: experience from an open-access clinic. Mult Scler J 21:67-75

53. Marrie RA, Reingold S, Cohen J, Stuve O, Trojano M, Sorensen PS, Cutter G, Reider N (2015) The incidence and prevalence of psychiatric disorders in multiple sclerosis: a systematic review. Mult Scler J 21:305-317

54. Marrie RA, Horwitz R, Cutter G, Tyry T, Campagnolo D, Vollmer $\mathrm{T}$ (2009) Comorbidity delays diagnosis and increases disability at diagnosis in MS. Neurology 72:117-124 
55. Thormann A, Sørensen PS, Koch-Henriksen N, Laursen B, Magyari M (2017) Comorbidity in multiple sclerosis is associated with diagnostic delays and increased mortality. Neurology 89:1668-1675

56. Harel Y, Barak Y, Achiron A (2007) Dysregulation of affect in multiple sclerosis: new phenomenological approach. Psychiatry Clin Neurosci 61:94-98

57. Solomon AJ, Corboy JR (2017) The tension between early diagnosis and misdiagnosis of multiple sclerosis. Nat Rev Neurol 13:567-572
58. Carson AJ, Stone J, Warlow C, Sharpe M (2004) Patients whom neurologists find difficult to help. J Neurol Neurosurg Psychiatry 75:1776-1778

59. McWhirter L, Ritchie C, Stone J, Carson A (2020) Functional cognitive disorders: a systematic review. Lancet Psychiatry 7:191-207 